\title{
Implementing the CLASS Act: Six Decisions for the Secretary of Health and Human Services
}

\author{
Joshua M. Wiener, PhD
}

\section{Summary}

This policy brief analyzes some of the major issues that must be decided in implementing the CLASS Act insurance program:

- How can adverse selection be prevented?

- What should actuaries assume in setting insurance premiums?

- What level of disability should be required to receive benefits?

- How will eligibility for benefits be determined?

- How much will the benefits be and what can they be used for?

- What should be the relationship between the CLASS insurance program and private long-term care insurance?

Title VIII of the Patient Protection and Affordable Care Act, the health care reform legislation passed by Congress and signed by President Obama in March 2010, establishes a voluntary public insurance program for long-term care, the Community Living Assistance Services and Supports (CLASS) Act. Championed by the late Senator Ted Kennedy, the CLASS Act is a "public option" for long-term care insurance. The CLASS Act has the potential to radically change long-term care financing over time; however, it received little attention during the health care reform debate, and few people outside of a handful of experts know about it. Like much of the health care reform legislation, the provisions of the CLASS Act give the Secretary of the US Department of Health and Human Services considerable discretion to shape the detailed provisions of the program.

\section{Rationale for the CLASS Act and Key Provisions}

Advocates for the CLASS Act note that nursing home and extensive home care can be very expensive (a year of nursing home care at private pay rates costs an average of $\$ 67,525$ per year, and home health agency aide care costs an average of $\$ 19$ per hour ${ }^{1}$ ); such services are beyond the financial reach of most Americans. Medicare does not cover long-term care, and Medicaid requires people to be poor or become poor paying for health and long-term care before it provides assistance. Only about $10 \%$ of the population age 65 and older and less than $1 \%$ of the nonelderly adult population have private long-term care insurance. As a result, long-term care is a catastrophic out-of-pocket cost for many older people.

While acknowledging the problems of the long-term care financing system, opponents of the CLASS Act argue that a public program is unnecessary and undesirable. They contend that a viable private market for long-term care insurance exists and that public policy initiatives should focus on increasing its market share. Opponents also cast doubt on whether the particular design of the CLASS Act insurance program would provide more affordable premiums than private sector plans and whether the program would be financially viable over time.

The CLASS Act draws heavily on the German and Japanese long-term care insurance programs. ${ }^{2,3}$ The box on the next page summarizes the main elements of the CLASS Act insurance program. Except for full-time students, only working people are eligible to enroll. Unlike private long-term care insurance policies, the CLASS insurance program does not require medical underwriting. Thus, people with disabilities who work will be able to enroll. (All users of long-term care have 
disabilities, but not all people with disabilities need long-term care.) In addition, benefits are provided on a lifetime basis rather than for a fixed number of years or expenditure level. This feature of the CLASS insurance program will be especially attractive to younger persons with long-term care needs, who could receive benefits for decades. After paying premiums for at least 5 years, enrollees who meet the disability benefit criteria will receive a regular cash benefit to help meet their longterm care needs. Although beneficiaries may use the cash to purchase services, an in-kind benefit is not available. The insurance program is financed entirely by premiums.

\section{Main Characteristics of the CLASS Act Insurance Program}

- The CLASS insurance program is designed to provide insurance coverage for people with disabilities who need long-term care.

- The CLASS insurance program is a government plan. It is the "public option" for long-term care.

- Enrollment is voluntary. However, all people who work for participating employers are automatically enrolled unless they choose not to participate.

- There is no medical underwriting, but there is a 5-year waiting period before individuals can be eligible for benefits.

- Initial enrollment is limited to people who are employed. Children, retirees, and people who are not working are not eligible (including spouses).

- To receive benefits, individuals must have a fairly severe level of disability.

- Benefits vary by level of disability, as determined by the Secretary of the Department of Health and Human Services, but will average at least $\$ 50$ per day.

- Insurance premiums are the sole source of financing. Very low premiums for full-time students and people with incomes below the federal poverty level will be financed by subsidies by other people enrolled in the program.

- No more than $3 \%$ of premiums may be used for administrative expense

\section{How Can Adverse Selection Be Prevented?}

Unlike public long-term care insurance programs in countries such as Japan, Germany, and The Netherlands, the CLASS insurance program does not require that everyone participate. Thus, the program is potentially subject to adverse selection that could drive up the cost of premiums and possibly create an insurance death spiral. Without medical underwriting to exclude them, people with disabilities who need long-term care-and those at high risk of needing long-term care-may disproportionately enroll in the program. If few people without disabilities enroll, the program's ability to spread the costs of people using benefits across a broad population will be limited and premiums will be high, potentially causing nondisabled people to not enroll or to disenroll.

The CLASS Act attempts to lessen adverse selection through the following strategies:

- With the exception of full-time students, enrollment is limited to people who are working. Retirees, people with disabilities who are not in the labor force, and nonworking spouses or partners cannot enroll, even with medical underwriting. This provision excludes most people who currently need long-term care services, reducing the amount of revenue that needs to be raised to pay for services but potentially causing resentment among excluded groups. Using a broad definition of disability, only about $19 \%$ of people with disabilities were working in April 2010. ${ }^{4}$ Although many people in need of services are excluded initially from the CLASS insurance program, the expectation is that over time, as enrollees age - and their risk for needing long-term care increases-the program will cover an increasing proportion of the population in need. Because most working people are unaware of the CLASS Act and of their risk of needing long-term care, a large-scale educational campaign will very likely be needed to ensure a high level of enrollment.

- For employers who agree to administer payroll deductions for insurance premiums, all workers will be automatically enrolled. Individuals who do not want to enroll may opt out, but they must explicitly decide to do so. This approach to increase enrollment rates draws on behavioral economics research on participation in 401(k) retirement plans, which found that retirement savings enrollment rates were much higher when 
employees were required to opt out rather than opt in. ${ }^{5}$ However, employers are not required to administer payroll deductions for employees. Some may choose not to participate because they do not want the administrative burden, they are philosophically opposed to a public long-term care insurance program, or they already offer their employees private long-term care insurance. Still others might avoid participation because their employees oppose automatic enrollment, and participation would lead to resentment of employees. Inducing employers to take on this administrative task will require an active marketing campaign to convince them that automatic enrollment is in their and their employees' best interest. For individuals who work for organizations that choose not to offer payroll deductions and automatic enrollment, the program will have to find ways to administer individual enrollment, perhaps through Social Security offices.

- To discourage people from waiting until they need long-term care before they enroll, the law stipulates that enrollees must pay premiums for at least 5 years before they are eligible for benefits. Moreover, individuals must work for at least 3 of the 5 years during this waiting period. For the purposes of determining eligibility, individuals must earn enough to have each quarter of that 3-year period credited for Social Security eligibility (that amount is $\$ 1,120$ per quarter in 2010). In addition, to retain coverage, individuals must continue to pay premiums after the 5-year period, even if they are no longer working. Failure to pay premiums terminates the insurance coverage.

\section{What Should Actuaries Assume in Setting Insurance Premiums?}

Financing for CLASS Act benefits comes entirely from premiums paid by enrollees, which may vary by age, as determined by the Secretary. The law requires the program to be fully self-financing over 75 years. No more than $3 \%$ of the premiums may be used to pay for administrative expenses, which is substantially below the $30 \%$ to $40 \%$ of premium for administrative expenses that is typical for individually purchased private long-term care insurance. Although in line with administrative expenses of Medicare, this low percentage may be problematic, especially during the early years of the program, when educating workers and employers about the program will be critical for its success.
To encourage enrollment of full-time students and people who work but have incomes below the federal poverty level, premiums for these groups will initially be only $\$ 5$ per month, far below the expected premiums for nonsubsidized groups. These premium subsidies, however, will be financed by other insurance enrollees, not by federal general revenues. This subsidy for low-income workers and full-time students may substantially raise the premiums for people who are not in those categories. The SCAN Foundation/Avalere Health premium simulator estimates average premiums for a voluntary long-term care insurance program with some features similar to those of the CLASS Act with a low-income subsidy to be about $50 \%$ higher than the premiums would be without a low-income subsidy. ${ }^{6}$

Setting the premiums is a classic "chicken and egg" problem. If actuaries assume that large numbers of people will enroll and stay enrolled-including substantial numbers without long-term care needs or with a low likelihood of having such needs-then premiums will be relatively low and large numbers of people, including those without current or anticipated long-term care needs, are likely to enroll. The SCAN Foundation/Avalere Health long-term care insurance simulator estimates that the average premium for a mandatory long-term care insurance program with some features similar to those of the CLASS Act to be one-fourth of what they would be for a voluntary program, primarily because more people without disabilities would be enrolled. ${ }^{6}$ Advocates for the CLASS Act point to the near-universal enrollment in Medicare Part B (largely physician services) and Part D (prescription drugs) as evidence that enrollment levels will be high for the CLASS Act.

Conversely, if actuaries assume that relatively few people without current or anticipated LTC needs will enroll and that most people with current or anticipated long-term care needs will enroll, then premiums will be high, and few people without current or anticipated needs will enroll. Premium estimators who argue this position note that voluntary enrollment in private longterm care insurance in employment settings is low, with generally only about $5 \%$ to $7 \%$ of workers enrolling. Premium estimates developed during the health care reform debate assumed low levels of enrollment, resulting in high average premiums, ranging from $\$ 123$ to $\$ 240$ per month. ${ }^{7-9}$ Premiums will vary by age and these 
previously estimated premiums are based on a fairly high average age.

A key problem for the CLASS Act program is that if premiums are at this latter level, they will be higher than premiums for private long-term care insurance for people without chronic conditions, long-term care needs, or disabilities. ${ }^{10}$ As a result, healthy workers may prefer to purchase less expensive policies in the private market. The initial premium might well create a self-fulfilling prophecy that could determine the program's success or failure. Again, the key to low premiums is convincing workers without current or anticipated long-term care needs that the CLASS insurance program meets an important need and does so at an affordable cost.

\section{What Level of Disability Should Be Required to Receive Benefits?}

The Affordable Care Act specifies that the Secretary of Health and Human Services must set an eligibility standard for the receipt of benefits that includes the following three criteria: (1) limitation in at least two or three of six activities of daily living (ADLs), (2) the need for substantial supervision to protect an individual from threats to personal safety that are caused by cognitive impairment, or (3) an impairment equivalent to these two disability levels. These standards closely follow those established under the Health Insurance Portability and Accountability Act of 1996 for IRS tax-qualified private long-term care insurance. The Secretary's choice of eligibility criteria involves a tradeoff between covering more people with long-term care needs but with higher insurance premiums versus covering fewer people but with lower insurance premiums.

If equity is to be maintained, then the eligibility standard across the three criteria needs to identify people with roughly the same level of service need. For example, using National Long-Term Care Channeling Demonstration data, Spector and Kemper found that people with one ADL limitation and cognitive impairment needed 40 hours of care, which was equivalent to persons with two or three ADL limitations without cognitive impairment. ${ }^{11}$ The challenge is to develop an equitable cut point to receive benefits that accounts for interactions between physical and cognitive impairment, particularly in individuals with medical needs.

\section{How Will Eligibility for Benefits Be Determined?}

The legislation requires the establishment of an eligibility assessment system, which will determine whether "an individual has a functional limitation, as certified by a licensed health care practitioner" that qualifies for benefits. One possibility is to establish a benefit eligibility determination process that relies heavily on documentation provided by the enrollee's medical provider, an approach modeled on cash disability insurance programs such as the Social Security Disability Insurance program. However, functional assessments are rarely included in medical records, and physicians lack expertise in conducting such assessments. In addition, medical providers would have little incentive not to certify individuals as meeting the criteria, potentially increasing improperly the number of people receiving benefits.

An alternative approach would have independent or insurance program staff conduct functional assessments, as is typically done in the Medicaid program when determining the need for long-term care services. Japan, Germany, and The Netherlands all depend on these types of independent functional assessments as a way to ensure that only people who meet the eligibility criteria receive benefits.

\section{How Much Will the Benefits Be and What Can They Be Used For?}

Benefits under the CLASS insurance program are cash rather than a specific set of covered services. Receipt of these benefits will not affect eligibility for government programs, such as Medicaid and Supplemental Security Income, and will not be considered income for tax purposes.

The average cash payment amount, set by the Secretary, initially will not be less than $\$ 50$ per day and will vary by level of need. Beneficiaries with a higher level of need will receive a higher payment than those with lesser needs. Thus, hypothetically, people with two ADLs could receive a benefit of $\$ 30$ a day, while people with four ADLs could receive an average benefit of $\$ 70$ a day, so long as the average of all payments was estimated to be $\$ 50$ a day. The benefit amount will increase annually by the Consumer Price Index. 
Although the average $\$ 50$ per day benefit payment level has been criticized as inadequate, it is paid every day that the individual qualifies for benefits, regardless of whether the individual uses services on that day. Many people receiving paid home care do not receive it every day. Moreover, $\$ 50$ a day ( $\$ 18,250$ a year) is about twice what Medicaid spends per year on participants in home- and community-based services waiver programs for people age 65 and older and nonelderly persons with physical disabilities. $^{12}$

The legislation specifies that the Secretary will establish two to six benefit levels, but it does not mandate a specific number or what the cash benefits will be for each level. Germany established three basic benefit levels for its public long-term care insurance program, which are linked to a set cash benefit or maximum cost of services for people with each level of disability. Although Japan's program does not provide a cash benefit, it has seven disability levels, with a maximum possible insurance expenditure for individuals at each level. ${ }^{2}$ Implementation of the CLASS Act may also draw on the experience of state Medicaid programs, which routinely link levels of need to specific expenditure levels as part of the service planning process.

Despite the legislation's repeated references to a "cash benefit," the statute is ambiguous about whether beneficiaries will have unlimited freedom as to how the money will be used. In Germany's program, the cash benefits can be used for whatever the beneficiary would like. This approach maximizes the ability of individuals to meet their unique long-term care needs and would make the benefit more akin to the Social Security disability benefit.

In contrast, in England and The Netherlands, as well as in Medicaid participant self-direction programs in the United States, beneficiaries can use the funds to purchase a very wide range of services and supports, but they must spend the funds on services and supports that can be broadly defined as long-term care. Restrictions on what the funds may be used for and the statutory requirement for documentation of expenditures may lessen concerns about improper use of the funds, but such requirements may increase administrative expenses for the program and administrative burden for beneficiaries unless funds are routinely handled by third-party fiscal agents.

\section{What Should Be the Relationship Between the CLASS Insurance Program and Private Long-Term Care Insurance?}

By expanding the government role, the CLASS Act will likely supplant private long-term care insurance to some extent. However, the CLASS Act deliberately leaves a substantial role for private long-term care insurance. Although benefits will vary by level of need, the CLASS Act is designed to provide only a basic benefit, not comprehensive coverage for long-term care services and supports. In particular, the CLASS insurance benefits are not enough to pay the costs of nursing home care. As a result, private insurers have the option to offer wraparound benefits to the CLASS insurance plan somewhat analogously to how private insurers provide supplemental coverage for Medicare. Indeed, some CLASS Act advocates argue that by better defining the need, the CLASS Act will increase demand for private long-term care insurance. Although the insurance industry has been skeptical of this argument, companies will no doubt be considering their options to see whether a wraparound product is feasible. Although the legislation does not appear to explicitly authorize the Secretary to set regulations regarding private longterm care insurance products, how the government implements the CLASS Act will have a profound impact on the private long-term care insurance market.

\section{Conclusions}

Inclusion of the CLASS Act in the final health care reform legislation was a surprise to many long-term care experts and advocates. Widespread consensus exists among both liberals and conservatives on the need to reduce reliance on institutional care and provide more home and community-based services and to give participants in public long-term care programs more choice and greater control over their services. However, little consensus exists on long-term care financing reform. States that have been active in delivery system reform have been silent on restructuring financing. Although Hawaii and Washington State debated public long-term care insurance programs over the last decade, neither state enacted a program. At the national level, little discussion of long-term care financing reform has occurred since the failure of the Clinton health care reform proposals in 1994. Indeed, to the extent that any debate has taken place at all, it has focused on ways 
to promote private long-term care insurance. Notably, however, although Congress passed large-scale tax changes in 2001,2002, and 2003, tax incentives for private long-term care insurance were not included.

Over the long run, the CLASS Act has the potential to shift the financing system from one based primarily on Medicaid, which is a means-tested welfare program, to one based on insurance principles where risks are spread among the insured. However, because initial enrollment is limited to people in the workforce, this will be a slow process at best. For workers in their 50s, it may be another 30 years or more before they start using long-term care to any great extent. And the legislation does not address the long-term care needs of the population currently retired or unable to work.

For advocates of social insurance, the voluntary enrollment aspect of the program is especially problematic. Unless large numbers of healthy people enroll, the premiums will be high and the program may be financially unsustainable. Thus, the success or failure of the CLASS Act will depend a great deal on (1) whether the general working population can be educated to recognize their risk of needing long-term care as they age, (2) whether they believe that the CLASS insurance program can help to meet future long-term care needsi.e., offers value for its cost, and (3) whether they can afford the premiums. If other parts of health reform work as intended, lower health care costs may make the CLASS insurance program affordable for more people. The choices that the government makes in implementing the CLASS Act will help determine its success or failure.

\section{References}

1. Genworth Financial. Genworth 2010 Cost of Care Survey. Richmond, VA: Genworth Financial; 2010 [cited 2010 Aug 27]. Available from: http://www.genworth.com/content/ etc/medialib/genworth_v2/pdf/ltc_cost_of_care.Par.14625. File.dat/2010_Cost_of_Care_Survey_Full_Report.pdf

2. Campbell JC, Ikegami N, Gibson MJ. Lessons from public long-term care insurance in Germany and Japan. Health Affairs. 2010 [cited 2010 Aug27];29(1):87-95. Available from: http://content.healthaffairs.org/cgi/reprint/29/1/87
3. Gibson MJ, Redfoot DL. Comparing long-term care in Germany and the United States: what can we learn from each other? Washington, DC: AARP; 2007 [cited 2010 Aug 27]. Available from: http://assets.aarp.org/rgcenter/ il/2007_19_usgerman_ltc.pdf

4. US Bureau of Labor Statistics. Table 6: employment status of the civilian population by sex, age, and disability status, not seasonally adjusted. Washington, DC: Bureau; 2010 [cited 2010 Aug 27]. Available from: http://www.bls.gov/ news.release/empsit.t06.htm

5. Madrian BC, Shea DF. The power of suggestion: inertia in 401(k) participation and savings behavior. Q J Econ. 2000;116(4):1149-87.

6. SCAN Foundation/Avalere Health. Long-term care policy simulator. Los Angeles: SCAN; 2010 [cited 2010 Aug 27]. Available from: http://www.ltcpolicysimulator.org

7. American Academy of Actuaries. Re: actuarial issues and policy implications of a federal long-term care insurance program; 2009 [cited 2010 Aug 27]. Available from: http://www.actuary.org/pdf/health/class_july09.pdf

8. Foster R. Estimated financial effects of the "America's Affordable Health Choices Act of 2009" (H.R. 3962), as passed by the House on November 7, 2009. Baltimore, MD: Centers for Medicare and Medicaid Services; 2009.

9. US Congressional Budget Office. Letter from Douglas Elmendorf, Director of the Congressional Budget Office, to Speaker Nancy Pelosi, House of Representatives, March 20, 2010. Washington, DC: US Congressional Budget Office; 2010 [cited July 2, 2010] Available from: http://www.cbo.gov/ftpdocs/113xx/doc11379/ AmendReconProp.pdf

10. Tumlinson A, Aguiar C, Watts MO. Closing the long-term care funding gap: the challenge of private long-term care insurance. Washington, DC: Kaiser Family Foundation; 2009 Jun [cited 2010 Aug 27]. Available from: http://www. kff.org/insurance/upload/Closing-the-Long-Term-CareFunding-Gap-The-Challenge-of-Private-Long-Term-CareInsurance-Report.pdf

11. Spector WD, Kemper P. Disability and cognitive impairment criteria: targeting those who need the most home care. Gerontologist. 1994;34(5):640-51.

12. Ng T, Harrington C, O'Malley M. Medicaid home and community-based service programs: data update. Washington, DC: Kaiser Family Foundation; 2009 Nov [cited 2010 Aug 27]. Available from: http://www.kff.org/ medicaid/upload/7720-03.pdf 


\section{About the Author}

Joshua Wiener, PhD, is an RTI International Distinguished Fellow and director of RTI's Aging, Disability, and Long-Term Care Program.

RTI Press Research Briefs and Policy Briefs are scholarly essays on policy, methods, or other topics relevant to RTI areas of research or technical focus.

RTI International, 3040 Cornwallis Road, PO Box 12194, Research Triangle Park, NC 27709-2194 USA

Tel: 919.541.6000 Fax:919.541.5985 E-mail: rtipress@rti.org Web site: www.rti.org

(2010 Research Triangle Institute. RTI International is a trade name of Research Triangle Institute.

All rights reserved. Please note that this document is copyrighted and credit must be provided to the authors and source of the document when you quote from it. You must not sell the document or make a profit from reproducing it. 